\title{
Psychosocial Challenges and Strategies for Coping with HIV Among Adolescents in Uganda: A Qualitative Study
}

\author{
Massy Mutumba, PhD, 1,2 José A. Bauermeister, $\mathrm{PhD}$, Victor Musiime, MD, 2,3 Judith Byaruhanga, ${ }^{2}$ \\ Kiweewa Francis, MD, ${ }^{4}$ Rachel C. Snow, DSc, ${ }^{1}$ and Alexander C. Tsai, MD ${ }^{5-7}$
}

\begin{abstract}
Although more than $90 \%$ of youth perinatally infected with HIV live in sub-Saharan Africa, little is known about the psychosocial factors that impact their wellbeing, or how these youth cope with these challenges. The purpose of this study was to identify the psychosocial challenges and coping strategies among perinatal HIVinfected adolescents in Uganda. In-depth interviews were conducted with a purposive sample of 38 HIVinfected adolescents aged 12-19 years at a large HIV treatment center in Kampala. Data were analyzed thematically to identify themes and domains related to stressors and specific coping strategies. Psychosocial challenges included stigma/discrimination, relationship challenges such as HIV status disclosure, and medication difficulties. Coping strategies included medication adherence, concealment or limited disclosure of HIV status, treatment optimism, social support, rationalizing, social comparison, spirituality/religiosity, avoidance, and distraction. Age and gender differences also emerged: younger participants generally lacked specific coping strategies; compared to females, male adolescents reported greater use of avoidance/distraction techniques. Findings underscore the need to address stigma within homes and schools, and to equip adolescents with the comprehensive knowledge and skills to address their varied challenges.
\end{abstract}

\section{Introduction}

A NTI-RETROVIRAL TREATMENT (ART) has dramatically reduced HIV/AIDS mortality and morbidity among HIVinfected persons, ${ }^{1,2}$ transforming HIV/AIDS from a death sentence into a chronic illness. At present, UNAIDS estimates that approximately 3.3 million children are living with HIV/ AIDS, $90 \%$ of whom live in sub-Saharan Africa. ${ }^{3}$ In 2012, approximately 2.1 million adolescents were living with $\mathrm{HIV}^{4}$ (ALH) worldwide. In Uganda, approximately 100,000150,000 are adolescents aged 10-19 years are living with HIV. $^{4}$ This population constitutes the maturing cohort of children perinatally infected with HIV. Despite advances in HIV care, ALH face numerous psychosocial challenges, arising from the complexities of negotiating the challenges of adolescence within the context of a highly stigmatized and life-threatening illness. ${ }^{5-8}$
HIV stigma has been defined as the social discrediting and devaluation of HIV-infected persons. ${ }^{9}$ For ALH, their HIV status is a concealable stigmatized identity $(\mathrm{CSI})^{10}$ but this does not mitigate the impact of HIV stigma. Stigma impacts HIV-infected persons through concomitant mechanisms specific to how people react to the knowledge that individuals either do (HIV-infected) or do not (HIV-uninfected) possess the devalued attributed. ${ }^{9,11-14}$ Among HIV-infected persons, there at least three important stigma mechanisms, including enacted stigma, anticipated stigma, and internalized stigma. These mechanisms manifest in three predominant ways: prejudice, stereotyping, and discrimination, 9,11,13,14 and may negatively affect the psychological, behavioral, and health outcomes of HIV-infected persons. HIV stigma has been associated with increased psychological distress, ${ }^{13,15}$ poor physical health and quality of life, ${ }^{16,17}$ low social support, ${ }^{18}$ and risky health behaviors such as medication hiding and

\footnotetext{
${ }^{1}$ Department of Health Behavior and Health Education, University of Michigan School of Public Health, Ann Arbor, Michigan.

${ }^{2}$ Joint Clinical Research Center, Kampala, Uganda.

${ }^{3}$ Department of Pediatrics, Makerere University College of Health Sciences, Kampala, Uganda.

${ }^{4}$ Makerere University Walter Reed Project, Kampala, Uganda.

${ }^{5}$ Mbarara University of Science and Technology, Mbarara, Uganda.

${ }^{6}$ Department of Psychiatry, Harvard Medical School, Boston, Massachusetts.

${ }^{7}$ Center for Global Health and Chester M. Pierce, MD Division of Global Psychiatry, Massachusetts General Hospital, Boston, Massachusetts.
} 
non-adherence to ART, ${ }^{19}$ and sexual risk-taking and nondisclosure of HIV status to sexual partners. ${ }^{11,20-23}$

Informed by the stress and coping theory, ${ }^{24}$ researchers have argued that stigma is a stressor that can upset the physical and psychological well-being of a person, and requires action to restore balance. ${ }^{25}$ To manage these stressful demands, individuals may employ different coping efforts, ${ }^{25}$ including problem-focused strategies directed at changing a stressful situation, or emotion-focused strategies directed at changing the way one thinks or feels about a stressful situation. ${ }^{25}$ Similar to persons living with other concealable stigmatized identities and who possess other chronic illnesses, ALH employ a variety of coping strategies including secrecy, denial, deception, social withdrawal, and social support, all of which have different implications for their well-being. The type and complexity of coping strategies may vary with the adolescent's age ${ }^{26-28}$ and gender. ${ }^{29,30}$ Consequently, it is vital to contextualize how age and gender influence the psychosocial challenges and coping strategies of ALH.

Understanding how stigma manifests in ALH's lives is important to developing effective programmatic or policy interventions. Only a few studies have explored the psychosocial challenges of ALH in sub-Saharan Africa highlighting stigma and discrimination, lack of medical adherence, concerns about HIV status disclosure, poverty, poor academic performance, and psychological distress as major challenges. ${ }^{31-34}$ Half of these studies is quantitative in nature, ${ }^{31,34}$ which limits our ability to have a rich description of how ALH cope with these psychosocial challenges. Therefore, the purpose of this article is to contribute to this literature by focusing on ALH in a resource-limited setting (Uganda) and highlighting both the stressors and coping strategies employed by ALH in order to identify and inform the development of evidence-based programs, as well as recommendations for future practice and research.

\section{Methods}

\section{Study design}

We conducted semi-structured interviews between August and November 2011 with a convenience sample of 38 perinatally HIV-infected adolescents receiving HIV care from Joint Clinical Research Center (JCRC), a large HIV treatment center in Kampala (the capital city of Uganda), which provides care to approximately $2000 \mathrm{HIV}$-infected children and adolescents. A purposive sampling strategy was used to ensure a balance of male and female respondents and a broad distribution of respondents across the age spectrum (13-19 years). ALH were eligible to participate in this study if they were 13-19 years of age, enrolled in care at the JCRC, and fully aware of their HIV status. A minimum age of 13 years was elected to ensure respondents had the cognitive capabilities to meet the broader aims of the study.

\section{Procedures}

Authors (MM and JB) approached potential respondents during their scheduled clinic visits. To avoid unplanned disclosures, each adolescent's disclosure status was verified by inquiring about the purpose of their visit to the clinic; only adolescents reporting HIV care as the reason for visiting the clinic were provided with information about the study. The research team monitored enrollment throughout the study and adjusted recruitment to ensure balance on these parameters (age and sex). Study recruitment ended when all emerging themes had been adequately explored and interviews did not yield any new theme, indicating saturation had been achieved (hence the final sample size of 38 respondents). MM and JB, both of whom have experience in qualitative research methods, conducted the interviews in English or Luganda (local language), depending on the adolescent's language preference. Interviews were conducted face-to-face in a quiet private room at the clinic; the authors utilized a semi-structured interview guide.

This study was part of a larger study exploring the lived experiences of perinatally infected HIV-positive adolescents in Uganda. Respondents were asked to describe the varied challenges they have encountered since learning of their HIV status. Follow-up probes were used to elicit HIV-related challenges if not spontaneously mentioned. Subsequently, respondents were asked to describe how they address these challenges and which coping strategies they have employed. The interviews generally lasted $30-45 \mathrm{~min}$ and were audiotaped. The tapes were transcribed verbatim, removing any personal identifying information. Interviews conducted in Luganda (four interviews) were transcribed in Luganda and then translated into English. Tapes were transcribed by a college student trained in secretarial studies, and the accuracy of the transcriptions was verified by MM and JB.

All participants provided informed assent and parental/ caregiver consent (if below 18 years of age) prior to participating in the study. Participants received 7 US dollars in contribution towards transportation costs. Ethical approval for this study was received from Joint Clinical Research Center and Uganda National Council for Science and Technology and University of Michigan Institutional Review Boards. Consistent with national guidelines, we received clearance for the study from the Uganda National Council for Science and Technology and from the Research Secretariat in the Office of the President.

\section{Data analysis}

Data analysis was grounded in the phenomenological approach to qualitative inquiry, which describes the meaning for several individuals of their lived experiences of a phenomenon. ${ }^{35}$ To avoid imposing existing theoretical frameworks or prioritizing respondents' experiences, this study utilized open thematic analysis ${ }^{36}$ to identify emerging themes. Two authors (MM and JB) individually conducted the initial close read of all the transcripts to familiarize themselves with the data, identify emerging themes, and mark appropriate text in the transcripts that exemplified each theme. Each author developed a set of codes individually and then met to compare themes. Codes were compared for differences and similarities, and then grouped into categories. Themes were generated based on interpretation of the underlying meaning of the categories. For example, codes such as separation of utensils, unequal treatment at home, and refusal to play with siblings were categorized as discrimination, and thematically interpreted as stigma. A coding scheme including a main theme, sub-themes and exemplary quotes was developed, and this was expanded as new themes emerged from the data during the transcript recode. MM and JB met weekly to compare themes and meaning in order to ensure uniformity in interpretation of codes. Codes were 
Table 1. Descriptive Characteristics OF RESPONDENTS

\begin{tabular}{lc}
\hline & Percentage (count) \\
\hline Age & $16.9(3.4)$ \\
Mean (SD) & \\
Sex & $52.6(20)$ \\
Females & $47.4(18)$ \\
Males & \\
Currently enrolled in school & $82(31)$ \\
Yes & $18(7)$ \\
No & \\
Orphanhood status & $18.4(7)$ \\
Both parents alive & $42.1(16)$ \\
Lost one parent & $39.5(15)$ \\
Lost both parents & \\
Type of caregiver & $44.7(16)$ \\
Biological parent & $15.8(6)$ \\
Uncles or aunties & $21.1(8)$ \\
Grandparents & $7.9(3)$ \\
Siblings & $13.2(5)$ \\
Other (e.g., group homes, & \\
$\quad$ good Samaritans) & \\
Average age at disclosure & $13.0(3.3)$ \\
Mean (SD) & \\
Average duration (years) & \\
since disclosure & \\
Mean (SD) & \\
Average duration (years) & \\
on anti-retroviral therapy & \\
Mean (SD) & \\
\hline
\end{tabular}

reviewed and evaluated to ensure inter-coder reliability, and any discrepancy was resolved through a team discussion.

In analyzing these data, we found that certain stigma and disclosure dominate the experiences of all respondents and impel most of the reported challenges; as such, the results are presented in order of the most dominant to least dominant themes to provide a logical narrative to respondents' experiences and avoid privileging experiences of the majority. Consistent with the stress and coping theory, we sought to identify problem-focused and emotion-focused coping strategies. During data analysis, we found that some efforts could be utilized as both problem-focused and emotion-focused coping strategies. For this reason, coping strategies are presented without distinction between problem-focused or emotionfocused efforts, even though the stress and coping theory conceptualizes these strategies as distinct functions.

\section{Results}

\section{Demographics}

A total of 38 adolescents participated in this study; 53\% were female. The average age of the participants was 16.9 years and $31(82 \%)$ participants were attending school. Other summary statistics are described in Table 1.

\section{Psychosocial challenges}

HIV stigma. Internalized stigma, anticipated stigma, and experienced stigma emerged as the main stressors described by participants. Several respondents reported feeling different from their peers due to their HIV status because of their illness and they also had to take medications to survive, and they had internalized negative stereotypes about HIV:

Up to now, I feel different from other children. Someone who looks miserable without HIV is far better than a person who looks healthy with HIV. [Who told you?] It's how I know it and I believe it's true (Female, $17 \mathrm{yrs}$ )

All respondents expressed concern and fear of gossiping, ridicule, teasing, and loss of friendships if their HIV status were to be known. Several participants reported experiencing discrimination in both school and home environments. At school, stigma was perpetuated by peers and teachers:

I don't want them [friends] to pity me and gossip about me (Female, 18 yrs)

At first, when I took those medications I was in boarding school. I was coughing all the time and children were laughing at me and I felt bad...I don't know how the matron got to know but she knew and told them...they back-bitted [gossiped] me whenever I passed (Female, $18 \mathrm{yrs}$ )

At home, acts of discrimination included separation of plates, utensils, and shower basins, as well as taunts about their status. A few respondents reported unequal treatment such as enrollment in inferior schools compared to non-HIVinfected children in the household and not being allowed to play with non-HIV-infected siblings. Respondents attributed this stigma and discrimination to lack of knowledge and misconceptions about HIV transmission.

Disclosure. Stigma also manifested as fear of unintentional disclosure of HIV status. This challenge was most frequently reported by adolescents attending boarding schools, where the lack of privacy in school dormitories and perceptions of lack of confidentiality among school staff heightened the risk of such unwanted disclosure. Adolescents went to great lengths to avoid acts that could arouse suspicions about their status, for example, by avoiding the use of noisy pill bottles, by not taking medications in the presence of their peers, or frequenting the school clinic, and by not associating with known HIV-positive peers, etc. Fear of disclosure was not limited to the school setting: several participants reported limited disclosure of their HIV status at home, and this secrecy was most often enforced at the request of the parent or caregiver. A few adolescents opted not to disclose their status to family members out of fear of possible discrimination, loss of information control, and a desire to avoid pity:

Even at home the children don't know. They see me and ask but mum tells them I have malaria and they don't care. Mum tells me not to tell them...maybe in the future. (Female, $18 \mathrm{yrs}$ )

A majority of respondents reported difficulty of disclosing their HIV status to peers and sexual partners as these could result in loss of friendships and lead to further stigmatization; others simply want to avoid pity or gossip:

It's very hard to tell people you are positive, you may even lose your friends. They may not live with people who are positive because they think they may get infected. Like at school, they give me some things and I also give them so they may fear to get infected. (Male, $14 \mathrm{yrs}$ ) 
I don't want them [friends] to pity me and gossip about me. (Female, 18 yrs)

The lack of disclosure reinforced adolescents' sense of isolation from both siblings and peers, heightened their emotional distress, and undermined their ability to adhere to their medications and seek social support, particularly when the lack of disclosure occurred within the family:

I have HIV and others don't have it especially at home. [How does that make you feel?] I feel bad a little. (Male, $19 \mathrm{yrs)}$

It's only my mother who knows and she is not at home all the time. (Male, $18 \mathrm{yrs}$ )

Fear of transmitting HIV to their sexual partners was also expressed in their narratives. Only three (all female) of the eleven respondents in a relationship had disclosed to their partner. The outcomes of these disclosures were all positive: two respondents had HIV-negative partners who chose to continue the relationship; the other respondent was not aware of her partner's status since he was afraid of testing. Other respondents in relationships also wished to disclose to their partners but they were afraid of abandonment or disclosure of their status to other people. However, these respondents were concerned about transmitting HIV to their partners:

[Do you have a boyfriend?] Yes. [Does he know your status?] No...someday I will look for ways because I have to tell him my status. [Do you know his status?] Yes, he tested and told me and he told me to also go and test but I pretended. [Are you planning to have sex with him?] No, I don't want to give him the disease. They say that people who had AIDS they keep quiet and give it to others but I don't want to give my boyfriend the disease; I want to first tell him [when do you plan to tell him?] I don't know but not now. (Female, $17 \mathrm{yrs}$ )

Adherence. Medication-related stressors also emerged as a common theme. A majority of respondents reported that it was burdensome to take medications every day, swallow big tablets, and experience medication side effects. These challenges were augmented by the fear of HIV-related stigma and lack of disclosure, which created an enormous obstacle to adolescents' medication adherence. Adolescents avoided taking medications in the presence of their peers to avoid questions about their health status. Several respondents reported intentionally missing or postponing doses, or even throwing away medications:

They [drugs] make me feel lazy. I get a feeling of like they are stuck in my throat even if they are not actually stuck there and then also I feel like vomiting. (Female, $18 \mathrm{yrs)}$

I cannot tell my friends about my status and to me that means I am not normal. I am also not free to take my drugs when everyone is watching. (Female, $18 \mathrm{yrs}$ )

You know you take them when everyone is looking especially in boarding school. I used to just throw them away. [Why?] I was scared for people to know I was infected...they would laugh at me. (Male, $18 \mathrm{yrs}$ )

Respondents' narratives also highlighted institutional barriers to adherence among school-going adolescents, with clear distinctions between adolescents attending day school and boarding school. For adolescents attending day school, adherence challenges were related to their daily routines such as waking up late or returning home late contributed to missed doses:

I have to take the medicine every morning then go to school but sometimes I am late so I forget. (Female, $14 \mathrm{yrs}$ )

Adolescents attending boarding schools faced challenges related to school structures and organization, including a lack of privacy in dormitories due to overcrowding, and school routines such as early morning classes that were also disruptive to adolescents' medication regimens, particularly if drug dosing times were later in the day. A few respondents in boarding school reported keeping their medications with nurses at the school clinic as a way of circumventing the lack of privacy in the dormitory, but these medications were occasionally inaccessible if the clinic was locked or the nurse was away. Other respondents were opposed to keeping their medication with the nurses for fear that the frequent visits to the clinic would arouse questions about their health status, leading to suspicions about HIV, or expressed concern that the nurses would reveal their HIV status to other people:

You know at school they chase us out of the dorms very early for preps and sometimes I leave my medicine behind when I can't go back and get it. (Female, $16 \mathrm{yrs}$ )

We have a hospital at school where I keep it so when the time reaches I go there and take it...sometimes the nurses are not there and the rooms where I keep it are locked so I have to wait there. [Why don't you take it in your room?] It's not safe there; first of all, we are many in the room. (Male, $18 \mathrm{yrs}$ ).

\section{Coping strategies}

Social comparison and rationalization. Some adolescents reported finding comfort in the knowledge that they were not the only persons living with HIV. This was particularly common among respondents whose parents/caregivers or siblings were also living with HIV, as they also provided support with medication adherence and information on positive living:

I am not the first and last person to have HIV. (Female, $15 \mathrm{yrs}$ )

I have my sister who is also on a lot of drugs and she is there at home. So she takes hers and I also take mine. (Female, $18 \mathrm{yrs}$ )

Comparison to both HIV-negative and HIV-positive peers was also common, particularly in relation to dealing with the hassles of taking medications every day, high pill burden, and even accepting their HIV status:

There are those who say that they are not infected but I look healthier than they are. (Female, $16 \mathrm{yrs}$ )

In fact I am happy with the drugs because some children take more than that. (Female, $17 \mathrm{yrs}$ )

I am happy with it because there are some diseases which are bigger than this disease like cancer. (Female, 18 yrs)

Treatment confidence. Anti-retroviral treatment (ART) emerged as an important accessory to coping with HIV. Treatment-related confidence was very high among respondents, as they were keenly aware of the importance of ART in reducing the risk of death, preventing recurrent illness, and prolonging their lives. ART was central to adolescent's strategy to avoiding stigma and discrimination as it reduced or eliminated any physical signs of HIV-infection, particularly skin lesions which could arouse suspicion about their 
HIV status, allowing respondents to blend in with their uninfected peers:

Taking my drugs because it gives me confidence that I will live. (Male, $19 \mathrm{yrs}$ )

I remember what they told me that I will be fine if I took my medicine. (Male, $18 \mathrm{yrs}$ )

You know at school there is a student in the same situation like me [HIV positive] and for them they have scars even. (Female, $15 \mathrm{yrs})$

For the majority of respondents, taking medications had become a matter of routine, having successfully integrated this task into their daily routine:

I have a clock but even if I don't look at it, I just know its time. (Female, $16 \mathrm{yrs}$ )

Since I began some years back, I am used to the time to take it so it is difficult to forget. (Male, $17 \mathrm{yrs)}$

Respondents also provided specific examples of techniques used to manage their medications and ensure adherence. Respondents in day schools relied on reminders including phone alarms and verbal reminders from parents/caregivers. Adolescents in boarding schools had developed specific strategies to deal with their unique circumstances, and these included: setting discrete phone alarms, carrying pills in their school bag, using pill bottles, keeping medications at the school clinic or seeking permission from school authorities to return to the dormitories during class time in order to take their medications:

Actually I have a bed rest permit so at 7 o'clock when others are in class, I go to the warden and he gives me the key to the dorm. So I pretend I am going to rest and I take my medicine. I told the warden I have problems with my heart. (Male, $16 \mathrm{yrs)}$

In a few instances, respondents reported receiving reminders from teachers and significant others, while others had disclosed to a trusted friend(s) to avoid hiding when taking their medications in the dormitory. Only one respondent had disclosed to a trusted teacher who could remind her to take their medications:

One time, they [friends] asked me why I have to take tablets all the time and I told them I have a heart problem but I told one of them the truth. I just felt like it. At school, we have this nurse who tells us to keep our drugs and not show them to anyone but since I am used, I just take them openly. (Female, $18 \mathrm{yrs}$ )

Avoidance and distraction. Respondents reported that health providers had counseled them to avoid worrying about their HIV status as it would lead to poor health outcomes such as poor drug response and early death. Majority of respondents engaged various techniques to "try and forget about being HIV positive," and also "to avoid worry." Distraction techniques included burying embedding oneself in work (academic or house chores), chatting with friends, listening to music, playing sports etc. The frequency of using avoidance and distraction techniques was highest among younger (12-14 years) and female respondents:

Sometimes you have to forget those things and live like others but in my heart I cannot forget. (Male, $14 \mathrm{yrs)}$

Secrecy. Another frequently utilized coping strategy was concealment of HIV status, either through non-disclosure, limited disclosure to a few trusted persons, or both. A few respondents resorted to social isolation in a bid to stem off questions about their illness.

I used to isolate myself from my friends. I felt like I was alone who had that disease and as I continued my studies, my friends told me about their situations and I could not tell them about mine because I was embarrassed. I felt good though and very close to them. (Male, 13 yrs)

Non-disclosure was utilized to avoid stigma and its consequences such as loss of friendships, gossip, or discrimination. Respondents who had not disclosed their status generally attributed their frequent illnesses or medication use to more socially acceptable diseases such as heart disease or sickle cell anemia.

I take my drugs and trust no body with my status. (Male, $17 \mathrm{yrs})$

They don't know I take this medicine. I always tell them I have some heart problems and you see I am not a talkative person at school so not many ask me. (Male, $18 \mathrm{yrs)}$

Social support. Limited disclosure occurred in the context of trusting relationships with peers, partners, teachers, health workers, and religious leaders. It was utilized to mobilize practical support (e.g., adherence support) and emotional support. HIV-related social support included help with remembering to take their medication, informational support about HIV, and emotional support to deal with the isolation or distress related to HIV:

I didn't find any problem [with the drugs] because my mum used to encourage me to take it a lot. She was also on drugs so whenever she took hers, I also took mine. (Female, $15 \mathrm{yrs}$ )

I am lucky that my aunt gives me a lot of company. Even if you are seated alone, she does not let you. She takes me for a walk and we chat. (Male, $18 \mathrm{yrs}$ )

I get advice from my counselors and my mum, and there is also a good friend of mine I told and she told me I will be fine I took my medicine. (Female, $17 \mathrm{yrs}$ )

Respondents also utilized limited disclosure to enhance bonding in personal relationships, for example, to remove any secrets between themselves and their peers or partners, yet only a minority of respondents reported seeking social support from peers and partners, and only if they had disclosed to these persons.

Spirituality and religiosity. Praying emerged as another important coping strategy. Respondents reported praying to God to give them the strength to persevere through challenges, and achieve their life aspirations. However, none of the respondents reported relying on prayer alone; as indicated in the exemplary quotes below, this mechanism was used in tandem with other coping mechanism:

My trust is in God and the fact that I take my medication. (Female, $16 \mathrm{yrs}$ )

I pray to God to give me the strength not to give up. (Female, $14 \mathrm{yrs})$

\section{Discussion}

Numerous studies have enumerated the HIV-related stressors and coping strategies of ALH in developed 
countries, ${ }^{7,8,37-43}$ but only a few studies have been conducted in resource-limited settings. ${ }^{22,31,44-46}$ Our study builds on this literature by providing a contextualized description of psychosocial challenges and coping strategies of ALH in a resource-limited setting. Similar to prior studies, ${ }^{41-43,47,48}$ HIV stigma within home and school contexts and medication difficulties remain pertinent issues for ALH in Uganda. The ubiquity of stigma in ALH's narrative is consistent with results of the HIV Stigma Index, which found that HIV-related stigma is still common is Uganda. ${ }^{49}$ ALH attributed stigma to the lack of knowledge or misconceptions about HIV. Indeed, results of household surveys in Uganda indicate low levels of comprehensive HIV knowledge among young people. ${ }^{50,51}$ Among persons living with HIV, stigma constrains access to social support within their networks, and increases risky health behaviors non-adherence to ART and unprotected sexual intercourse. ${ }^{45,52,53}$ However, the effects of HIV stigma extend beyond the needs of persons living with HIV: stigma has been shown to impact utilization of health services including HIV testing and treatment ${ }^{49,54,55}$ and discourage positive health behaviors such as disclosure to sexual partners. ${ }^{56-58}$

Respondents utilized a number of strategies to cope with these challenges, including treatment optimism, secrecy, avoidance and distraction, social support, social comparison and rationalization, and spirituality/religiosity. These coping strategies are consistent with the stress and coping literature to the extent that they could be categorized as problem focused strategies (e.g., adherence skills, mobilizing social support), or emotion-focused strategies (e.g., distraction and avoidance, rationalization and social comparison, spirituality and religiosity).

The challenges and coping strategies highlighted in this study have also been identified among persons living with other concealable stigmatized identities. ${ }^{13,14}$ We found that experiences of enacted, anticipated, and internalized stigma were common in ALH's daily life experiences. Enacted stigma was evident in respondents' narrative of separation of household utensils, bullying and gossiping by peers, and limited socialization within their homes and schools. These events were often mentioned as leading to distress, concealment of HIV status, and non-adherence to ART. Internalized stigma, manifested in respondents' endorsement of negative statements and attributes about HIV-infected persons, affected ALH's self-worth and self-esteem. Anticipated stigma, including fear of discrimination and fear of being ostracized due to internalized stigma and the perceived inevitability of enacted stigma, was also discussed as influencing disclosure to peers and sexual partners as well as non-adherence to ART. The consequences of HIV-related stigma documented in this study are consistent with reports from prior studies: emotional distress, ${ }^{31,59-61}$ poor adherence to ART, ${ }^{42,45,62-64}$ nondisclosure of HIV status to sexual partners, ${ }^{52,65}$ and constrained access to social support; ${ }^{42,45,64}$ all of these outcomes are serious public health implications including poor virologic suppression and immunologic responses to ART, leading to drug resistance and accelerated progression to AIDS, ${ }^{45,60,63}$ and an increased risk of transmitting HIV. ${ }^{65,66}$

The home and school environments are the most salient socio-ecological contexts for adolescent wellbeing and development. Arguably, the presence of adversity within these contexts undermines the well-being of all ALH. Adolescents living with a chronic illness typically rely on their families for social support. ${ }^{7,67}$ In our study, ALH noted how they are unable to disclose their status and fear discrimination from family members. ALH attributed the nondisclosure or limited social disclosure of their HIV status to their parent/caregiver's concerns about potential discrimination within the home. Respondents' narratives on stigma and its consequent outcomes including the limited social disclosure of HIV status within their households and among peers highlight the delicate fragility of ALH social support networks, which has several implications for their health and wellbeing.

Among perinatally-infected ALH, there is often an intrinsic relationship between the parents' and adolescent's HIV status-disclosure of the ALH's status may inevitable disclose the parent's own status. Therefore, the lack or limited disclosure of ALH's status may reflect the parent's concern about revealing their own HIV status (if they have not yet disclosed), fear of alerting other children in the family of their potential HIV infection, or be attributed to the parent or caregivers' personal struggle with the management of HIV within the family system. Even for nonHIV infected caregivers, concerns about the possibility of associative stigma, that is, stigma resulting from their close relation to a person living with $\mathrm{HIV},{ }^{13}$ may result in enacted stigma toward ALH. Future research examining the role of stigma on ALH's family dynamics and social support provision is warranted. For example, it remains unclear whether the inconsistency in prior studies regarding the relevance of social support to ALH's wellbeing $39,53,68$ could be confounded by experiences of stigma within the family system. By examining these complex relationships, researchers and practitioners may be able to develop interventions to address family-based stigma and enhance the provision of social support to ALH.

Our analysis found that stigma within schools represents a serious challenge for ALH. In Uganda, adolescents attending day schools spend more than $10 \mathrm{~h}$ a days in these contexts, or live in boarding schools. The experience of enacted stigma within this context even more distressing because ALH may not have safe spaces to build community, disclose, or take their medication. Further, adolescents' narratives highlight how some ALH felt that adults within the schools (e.g., teachers, school nurses) may not be particularly responsive to their needs. The consequences of stigma within schools should not be taken lightly as it has deleterious effects on ALH's well-being, including their adherence to ART and school engagement. In this study, several respondents reported the changing schools, being unable to concentrate in class, and withdrawing from class participation following involuntary public disclosure of their HIV status to peers. Although the emphasis on ALH's well-being tends to focus on their health status, these findings also suggest that ALH's psychosocial development (e.g., academic achievement) may be compromised due to stigma.

In Uganda, only two published interventions have attempted to address HIV stigma, ${ }^{69,70}$ yet neither focused on stigma within schools. Although HIV education is part of the school curriculum in Uganda, ${ }^{71,72}$ the impact of what is discussed and how it is delivered on HIV stigma is not clear. For example, lessons often focus on imparting knowledge about HIV transmission and prevention, rather than creating contexts where youth may learn and question the social 
processes that produce or reinforce HIV-related stigma or understand the effect of stigma on persons living with HIV. An evaluation of the school based HIV and AIDS curriculum in Uganda reinforces our concern, as the evaluation found that the curriculum was not effective due to lack of classroom time and fear of controversy among teachers. ${ }^{72}$ Therefore, our study findings also suggest a need for future research to identify strategies to reduce HIV-related stigma within schools settings and to mobilize social support.

Our study findings highlight several challenges that are unique to developmental stage of ALH including structural barriers in the family and school setting. However, it is important to note that not all disclosures of HIV status had negative outcomes. In this study, respondents who narrated disclosing their HIV status to sexual partners reported positive outcomes from their disclosures. This finding is consistent with results of prior studies conducted in Uganda. ${ }^{57}$ Disclosure of HIV status is critical to preventing HIV transmission among sero-discordant couples. ${ }^{73,74}$ Success stories of positive outcomes following disclosure to sexual partners could go a long way in advancing stigma reduction messages, and promoting disclosure among people living with HIV who are reluctant or fearful of negative repercussions (e.g., violence, rejection). In order to build interventions that could promote such positive outcomes, future research examining what qualities or attributes within these relationships helped to promote disclosure and to mitigate potentially negative outcomes is warranted. Our study findings suggest that the psychosocial challenges of ALH globally do not differ markedly, particularly when it comes to issues such as medication adherence, stigma and discrimination, and mental health disorders. As such, existing interventions such as EVOLUTION $^{75}$ have potential applications among ALH in Uganda, if adapted to the local context.

Interpretation of our findings is subject to several limitations. Our qualitative study recruited a convenience sample of ALH who attend a large urban HIV treatment center. As such, the respondents' experiences may differ from adolescents living in rural areas or who do not have access to a local treatment center. Nevertheless, our study highlights several opportunities to promote the well-being of ALH, including interventions aimed at promoting disclosure within homes, addressing parental attitudes towards disclosure, ${ }^{52,76}$ eliminating stigma within schools, harnessing the potential support of teachers and school clinic nurses in promoting adherence, and providing social support to ALH. These findings provide information that could facilitate comprehensive assessment of ALH's needs and inform also developing intervention strategies. This is particularly noteworthy given the paucity of evidence-based health interventions for ALH in resource limited settings.

There is a need to develop and evaluate psychosocial interventions for ALH in Uganda. Taken together, our results underscore the need to intensify efforts to promote HIV and AIDS knowledge, clarify misconceptions about HIV, and reduce HIV stigma in Uganda. These effects will be helpful in addressing stigma within homes and school settings. Educational programs about stigma have the potential to normalize stigmatized identities and communicate the value of persons living with HIV to ALH, their peers, and broader communities. Lastly, addressing stigma may require enacting policies to prevent discrimination of persons living with HIV.

\section{Acknowledgments}

This study was facilitated through grants from various institutions at University of Michigan including the African Studies Center and Rackham School of Graduate Studies. We are especially grateful for the management and staff at the JCRC, particularly those in the Pediatric Clinic for their willingness to share their time and insights. A special thanks also to all the respondents, who so willingly labored through the interviews and focus group discussions to share their unique insights.

\section{Author Disclosure Statement}

No competing financial interests exist.

\section{References}

1. Lima VD, Harrigan R, Bangsberg DR, et al. The combined effect of modern highly active antiretroviral therapy regimens and adherence on mortality over time. J Acq Immune Defic Syndromes (1999) 2009;50:529.

2. Baker JV, Peng G, Rapkin J, et al. CD4 + count and risk of non-AIDS diseases following initial treatment for HIV infection. AIDS (London, England) 2008;22:841.

3. UNAIDS. Global Report: UNAIDS Report on the Global AIDS Epidemic 2013: UNAIDS, 2013.

4. UNICEF. Monitoring the situation of children and women. $<$ http://data.unicef.org/hiv-aids/adolescents-young-people> (Last accessed September 15, 2014).

5. Arnett J. Socialization and adolescent reckless behavior: A reply to Jessor. Devel Rev 1992;12:391-409.

6. Muuss REH. Stanley Hall's Biogenetic Pyschology of Adolescents. In: R.E.H. Muuss, ed. Theories of Adolescence, 6th Ed. New York: McGraw-Hill, 1996:15-17.

7. Battles HB, Wiener LS. From adolescence through young adulthood: Psychosocial adjustment associated with longterm survival of HIV. J Adoles Health 2002;30:161-168.

8. DeLaMora P, Aledort N, Stavola J. Caring for adolescents with HIV. Curr HIV/AIDS Rep 2006;3:74-78.

9. Earnshaw VA, Chaudoir SR. From conceptualizing to measuring HIV stigma: A review of HIV stigma mechanism measures. AIDS Behav 2009;13:1160-1177.

10. Crocker J, Major B, Steele C. Social stigma: The psychology of marked relationships. Handbook Soc Psychol 1998: 504-553.

11. Tsai AC, Bangsberg DR, Kegeles SM, et al. Internalized stigma, social distance, and disclosure of HIV seropositivity in rural Uganda. Ann Behav Med 2013;46:285-294.

12. Herek GM, Capitanio JP. Symbolic prejudice or fear of infection? A functional analysis of AIDS-related stigma among heterosexual adults. Basic Appl Soc Psychol 1998;20:230-241.

13. Quinn DM, Chaudoir SR. Living with a concealable stigmatized identity: The impact of anticipated stigma, centrality, salience, and cultural stigma on psychological distress and health. J Personal Soc Psychol 2009;97:634.

14. Quinn DM, Earnshaw VA. Understanding concealable stigmatized identities: The role of identity in psychological, physical, and behavioral outcomes. Soc Issues Policy Rev 2011;5:160-190.

15. Wiener LS, Battles HB, Heilman N. Public disclosure of a child's HIV infection: Impact on children and families. AIDS Patient Care STDs. 2000;14:485-497.

16. Holzemer WL, Uys LR, Chirwa ML, et al. Validation of the HIV/AIDS Stigma Instrument-PLWA (HASI-P). AIDS Care 2007;19:1002-1012. 
17. Kalichman SC, Simbayi LC, Cloete A, Mthembu PP, Mkhonta RN, Ginindza T. Measuring AIDS stigmas in people living with HIV/AIDS: The Internalized AIDSRelated Stigma Scale. AIDS Care 2009;21:87-93.

18. Takada S, Weiser SD, Kumbakumba E, et al. The dynamic relationship between social support and HIV-related stigma in rural Uganda. Ann Behav Med 2014;48:26-37.

19. Calabrese SK, Martin S, Wolters PL, Toledo-Tamula MA, Brennan TL, Wood LV. Diagnosis disclosure, medication hiding, and medical functioning among perinatally infected, HIV-positive children and adolescents. AIDS Care 2012;24:1092-1096.

20. Mellins CA, Tassiopoulos K, Malee K, et al. Behavioral health risks in perinatally HIV-exposed youth: Co-occurrence of sexual and drug use behavior, mental health problems, and nonadherence to antiretroviral treatment. AIDS Patient Care STDs 2011;25:413-422.

21. Hightow-Weidman LB, Phillips II G, Outlaw AY, et al. Patterns of HIV disclosure and condom use among HIVinfected young racial/ethnic minority men who have sex with men. AIDS Behav 2013;17:360-368.

22. Bakeera-Kitaka S, Nabukeera-Barungi N, Nöstlinger C, Addy K, Colebunders R. Sexual risk reduction needs of adolescents living with HIV in a clinical care setting. AIDS Care 2008;20:426-433.

23. Birungi H, Mugisha JF, Obare F, Nyombi JK. Sexual behavior and desires among adolescents perinatally infected with human immunodeficiency virus in Uganda: Implications for programming. J Adolesc Health 2009;44:184-187.

24. Lazarus RS, Folkman S. Stress, Appraisal, and Coping. New York Springer Publishing Company, 1984.

25. Lazarus RS. Coping theory and research: Past, present, and future. Psychosom Med 1993;55:234-247.

26. Snethen J, Broome ME, Kelber S, Warady B. Coping strategies utilized by adolescents with end stage renal disease. Nephrol Nursing J 2004;31:41-52.

27. Knapp LG, Stark LJ, Kurkjian JA, Spirito A. Assessing coping in children and adolescents: Research and practice. Edu Psychol Rev 1991;3:309-334.

28. Keller C, Nicolls R. Coping strategies of chronically ill adolescents and their parents. Issues Comp Pediatr Nursing 1990;13:73-80.

29. Spirito A, Stark LJ, Gil KM, Tyc VL. Coping with everyday and disease-related stressors by chronically ill children and adolescents. J Am Acad Child Adolesc Psychiatr 1995; 34:283-290.

30. Bull BA, Drotar D. Coping with cancer in remission: Stressors and strategies reported by children and adolescents. J Pediatr Psychol 1991;16:767-782.

31. Cluver LD, Gardner F, Operario D. Effects of stigma on the mental health of adolescents orphaned by AIDS. $\underline{\text { J Adolesc }}$ Health 2008;42:410-417.

32. Bakeera-Kitaka S, Nabukeera-Barungi N, Nastlinger C, Addy K, Colebunders R. Sexual risk reduction needs of adolescents living with HIV in a clinical care setting. AIDS Care 2008;20:426-433.

33. Siu GE, Bakeera-Kitaka S, Kennedy CE, Dhabangi A, Kambugu A. HIV serostatus disclosure and lived experiences of adolescents at the Transition Clinic of the Infectious Diseases Clinic in Kampala, Uganda: A qualitative study. AIDS Care 2012;24:606-611.

34. Cluver L, Gardner F, Operario D. Poverty and psychological health among AIDS-orphaned children in Cape Town, South Africa. AIDS Care 2009;21:732-741.
35. Creswell JW. Qualitative Inquiry and Research Design: Choosing among Five Approaches. Sage Publications: Thousand Oaks, CA, 2012.

36. Boyatzis RE. Transforming Qualitative Information: Thematic Analysis and Code Development. Sage Publications: Thousand Oaks, CA, 1998.

37. Murphy DA, Moscicki AB, Vermund SH, Muenz LR. Psychological distress among HIV-positive adolescents in the REACH study: Effects of life stress, social support, and coping. J Adolesc Health 2000;27:391-398.

38. Murphy DA, Wilson C, Durako S, Muenz L, Belzer M. Antiretroviral medication adherence among the REACH HIV-infected adolescent cohort in the USA. AIDS Care 2001;13:27-40.

39. Naar-King S, Templin T, Wright K, Frey M, Parsons JT, Lam P. Psychosocial factors and medication adherence in HIV-positive youth. AIDS Patient Care STDs 2006;20: 44-47.

40. Meijer SA, Sinnema G, Bijstra JO, Mellenbergh GJ, Wolters WH. Coping styles and locus of control as predictors for psychological adjustment of adolescents with a chronic illness. Soc Sci Med 2002;54:1453-1461.

41. Martinez J, Lemos D, Hosek, the Adolescent Medicine Trials Network S. Stressors and sources of support: The perceptions and experiences of newly diagnosed Latino youth living with HIV. AIDS Patient Care STDs 2012;26: 281-290.

42. Michaud P-A, Suris J-C, Thomas R, Gnehm HE, Cheseaux J-J. Coping with an HIV infection. A multicenter qualitative survey on HIV positive adolescents' perceptions of their disease, therapeutic adherence and treatment. Schweiz Med Wochenschrift 2010;140:247-253.

43. Orban LA, Stein R, Koenig LJ, et al. Coping strategies of adolescents living with HIV: Disease-specific stressors and responses. AIDS Care 2010;22:420-430.

44. Ayres JRdCM, Paiva V, França Jr I, et al. Vulnerability, human rights, and comprehensive health care needs of young people living with HIV/AIDS. Am J Public Health 2006;96:1001.

45. Rao D, Kekwaletswe T, Hosek S, Martinez J, Rodriguez F. Stigma and social barriers to medication adherence with urban youth living with HIV. AIDS Care 2007;19:28-33.

46. Campbell C, Foulis CA, Maimane S, Sibiya Z. "I have an evil child at my house": Stigma and HIV/AIDS management in a South African community. Am J Public Health 2005;95:808.

47. Green G, Smith R. The psychosocial and health care needs of HIV-positive people in the United Kingdom: A review. HIV Med 2004;5:4-46.

48. Dodds S, Blakley T, Lizzotte J, et al. Retention, adherence, and compliance: Special needs of HIV-infected adolescent girls and young women. J Adolesc Health 2003; 33:39-45.

49. The National Forum of People Living with HIV Networks in Uganda (NAFOPHANU). The PLHIV Stigma Index, Country Assessment, Uganda. Kampala, Uganda: The National Forum of People Living with HIV Networks in Uganda (NAFOPHANU), 2013.

50. UNICEF. Uganda Statistics. Statistics http://www.unicef .org/infobycountry/uganda_statistics.html (Last accessed September 15, 2014).

51. Uganda Bureau of Statistics (UBOS), ICF International Inc. Uganda Demographic and Health Survey 2011. Kampala, Uganda and Calverton, Maryland: ICF International Inc, 2012. 
52. Michaud P-A, Suris J-C, Thomas LR, Kahlert C, Rudin C, Cheseaux J-J. To say or not to say: A qualitative study on the disclosure of their condition by human immunodeficiency virus-positive adolescents. J Adolesc Health 2009; 44:356-362.

53. Lam PK, Naar-King S, Wright K. Social support and disclosure as predictors of mental health in HIV-positive youth. AIDS Patient Care STDs 2007;21:20-29.

54. Turan JM, Bukusi EA, Onono M, Holzemer WL, Miller S, Cohen CR. HIV/AIDS stigma and refusal of HIV testing among pregnant women in rural Kenya: Results from the MAMAS Study. AIDS Behav 2011;15:1111-1120.

55. Kalichman SC, Simbayi LC. HIV testing attitudes, AIDS stigma, and voluntary HIV counselling and testing in a black township in Cape Town, South Africa. Sex Trans Inf 2003;79:442-447.

56. Kilewo C, Massawe A, Lyamuya E, et al. HIV counseling and testing of pregnant women in sub-Saharan Africa: Experiences from a study on prevention of mother-to-child HIV-1 transmission in Dar es Salaam, Tanzania. J Acq Immune Defic Syndromes 2001;28:458-462.

57. King R, Katuntu D, Lifshay J, et al. Processes and outcomes of HIV serostatus disclosure to sexual partners among people living with HIV in Uganda. AIDS Behav 2008;12:232-243.

58. Tsai AC, Bangsberg DR, Kegeles SM, et al. Internalized stigma, social distance, and disclosure of HIV seropositivity in rural Uganda. Ann Behav Med 2013;46:285-294.

59. Tsai AC, Bangsberg DR, Frongillo EA, et al. Food insecurity, depression and the modifying role of social support among people living with HIV/AIDS in rural Uganda. Soc Sci Med 2012;74.

60. Skinner D, Mfecane S. Stigma, discrimination and the implications for people living with HIV/AIDS in South Africa: Original article. SAHARA: Journal of Social Aspects of HIV/AIDS Research Alliance 2004;1:157-164.

61. Akena D, Musisi S, Joska J, Stein DJ. The association between AIDS related stigma and major depressive disorder among HIV-positive individuals in Uganda. PloS One 7 2012;11:e48671.

62. Katz IT, Ryu AE, Onuegbu AG, et al. Impact of HIVrelated stigma on treatment adherence: Systematic review and meta-synthesis. J Intl AIDS Soc 2013;16:18640.

63. Mills EJ, Nachega JB, Buchan I, et al. Adherence to antiretroviral therapy in sub-Saharan Africa and North America: A meta-analysis. JAMA 2006;296:679-690.

64. Pugatch D, Bennett L, Patterson D. HIV medication adherence in adolescents: A qualitative study. J HIV/AIDS Prev Edu Adolesc Children 2002;5:9-29.

65. Fideli ÜS, Allen SA, Musonda R, et al. Virologic and immunologic determinants of heterosexual transmission of human immunodeficiency virus type 1 in Africa. AIDS Res Human Retroviruses 2001;17:901-910.
66. Quinn TC, Wawer MJ, Sewankambo N, et al. Viral load and heterosexual transmission of human immunodeficiency virus type 1. N Engl J Med 2000;342:921-929.

67. Kyngäs H. Support network of adolescents with chronic disease: Adolescents' perspective. Nurs Health Sci 2004;6: 287-293.

68. Murphy DA, Moscicki AB, Vermund SH, Muenz LR. Psychological distress among HIV positive adolescents in the REACH study: Effects of life stress, social support, and coping. J Adolesc Health 2000;27:391-398.

69. Kaleeba N, Kalibala S, Kaseje M, et al. Participatory evaluation of counselling, medical and social services of The AIDS Support Organization (TASO) in Uganda. AIDS Care 1997;9:13-26.

70. Neema S, Atuyambe LM, Otolok-Tanga B, et al. Using a clinic based creativity initiative to reduce HIV related stigma at the Infectious Diseases Institute, Mulago National Referral Hospital, Uganda. African Health Sci 2012;12: 231-239.

71. Barnett E, de Koning K, Francis V. Health \& HIV/AIDS Education in Primary \& Secondary Schools in Africa \& Asia. Policies, Practice \& Potential: Case Studies from Pakistan, India, Uganda, Ghana. Education Research: ERIC, 1995.

72. Kinsman J, Nakiyingi J, Kamali A, et al. Evaluation of a comprehensive school-based AIDS education programme in rural Masaka, Uganda. Health Edu Res 2001;16:85-100.

73. Duru OK, Collins RL, Ciccarone DH, et al. Correlates of sex without serostatus disclosure among a national probability sample of HIV patients. AIDS Behav 2006;10:495-507.

74. Klitzman R, Exner T, Correale J, et al. It's not just what you say: Relationships of HIV dislosure and risk reduction among MSM in the post-HAART era. AIDS Care 2007; 19:749-756.

75. Brothers J, Harper GW, Fernandez MI, Hosek SG; Adolescent Trials Network for HIV/AIDS Interventions. EVOLUTION-Taking charge and growing stronger: The design, acceptability, and feasibility of a secondary prevention empowerment intervention for young women living with HIV. AIDS Patient Care STDs 2014;28:33-42.

76. Hogwood J, Campbell T, Butler S. I wish I could tell you but I can't: Adolescents with perinatally acquired HIV and their dilemmas around self-disclosure. Clin Child Psychol Psychiatr 2013;18:44-60.

Address correspondence to: Massy Mutumba, MD

Department of Health Behavior and Health Education University of Michigan School of Public Health 1415 Washington Heights Ann Arbor, Michigan 48104-2029

E-mail: massymutumba@umich.edu 


\section{This article has been cited by:}

1. Massy Mutumba, Jose A. Bauermeister, Gary W. Harper, Victor Musiime, James Lepkowski, Ken Resnicow, Rachel C. Snow. 2017. Psychological distress among Ugandan adolescents living with HIV: Examining stressors and the buffering role of general and religious coping strategies. Global Public Health 12:12, 1479-1491. [Crossref]

2. Morenike O. Folayan, Carlos F. Cáceres, Nadia A. Sam-Agudu, Morolake Odetoyinbo, Jamila K. Stockman, Abigail Harrison. 2017. Psychological Stressors and Coping Strategies Used by Adolescents Living with and Not Living with Hiv Infection in Nigeria. AIDS and Behavior 21:9, 2736-2745. [Crossref]

3. Winnie K Luseno, Bonita Iritani, Susannah Zietz, Suzanne Maman, Isabella I Mbai, Florence Otieno, Barrack Ongili, Denise Dion Hallfors. 2017. Experiences along the HIV care continuum: perspectives of Kenyan adolescents and caregivers. African Journal of AIDS Research 16:3, 241-250. [Crossref]

4. Nataly Woollett, Lucie Cluver, Monica Bandeira, Heena Brahmbhatt. 2017. Identifying risks for mental health problems in HIV positive adolescents accessing HIV treatment in Johannesburg. Journal of Child \& Adolescent Mental Health 29:1, 11-26. [Crossref]

5. Phung Khanh Lam, Sarah Fidler, Caroline Foster. 2017. A review of transition experiences in perinatally and behaviourally acquired HIV-1 infection; same, same but different?. Journal of the International AIDS Society 20:0. . [Crossref]

6. Nataly Woollett, Vivian Black, Lucie Cluver, Heena Brahmbhatt. 2017. Reticence in disclosure of HIV infection and reasons for bereavement: impact on perinatally infected adolescents' mental health and understanding of HIV treatment and prevention in Johannesburg, South Africa. African Journal of AIDS Research 16:2, 175-184. [Crossref]

7. Habib O. Ramadhani, Charles Muiruri, Venance P. Maro, Balthazar Nyombi, Michael Omondi, Julian B. Mushi, Eileen S. Lirhunde, John A. Bartlett. 2017. Patient-Initiated Repackaging of Antiretroviral Therapy, Viral Suppression and Drug Resistance. AIDS and Behavior . [Crossref]

8. Shannon Williams, Jenny Renju, Ludovica Ghilardi, Alison Wringe. 2017. Scaling a waterfall: a meta-ethnography of adolescent progression through the stages of HIV care in sub-Saharan Africa. Journal of the International AIDS Society 20:1, 21922. [Crossref]

9. Jessica E. Haberer, Lora Sabin, K. Rivet Amico, Catherine Orrell, Omar Galárraga, Alexander C. Tsai, Rachel C. Vreeman, Ira Wilson, Nadia A. Sam-Agudu, Terrence F. Blaschke, Bernard Vrijens, Claude A. Mellins, Robert H. Remien, Sheri D. Weiser, Elizabeth Lowenthal, Michael J. Stirratt, Papa Salif Sow, Bruce Thomas, Nathan Ford, Edward Mills, Richard Lester, Jean B. Nachega, Bosco Mwebesa Bwana, Fred Ssewamala, Lawrence Mbuagbaw, Paula Munderi, Elvin Geng, David R. Bangsberg. 2017. Improving antiretroviral therapy adherence in resource-limited settings at scale: a discussion of interventions and recommendations. Journal of the International AIDS Society 20:1, 21371. [Crossref]

10. Esther Dusabe-Richards, Rwamahe Rutakumwa, Flavia Zalwango, Allen Asiimwe, Elvis Kintu, Fatuma Ssembajja, Janet Seeley. 2016. Dealing with disclosure: Perspectives from HIV-positive children and their older carers living in rural south-western Uganda. African Journal of AIDS Research 15:4, 387-395. [Crossref]

11. Kathleen M. Malee, Renee A. Smith, Claude A. Mellins. 2016. Brain and Cognitive Development Among U.S. Youth With Perinatally Acquired Human Immunodeficiency Virus Infection. Journal of the Pediatric Infectious Diseases Society 5:suppl 1, S1S5. [Crossref]

12. Megan K. Ramaiya, Kristen A. Sullivan, Karen O' Donnell, Coleen K. Cunningham, Aisa M. Shayo, Blandina T. Mmbaga, Dorothy E. Dow. 2016. A Qualitative Exploration of the Mental Health and Psychosocial Contexts of HIV-Positive Adolescents in Tanzania. PLOS ONE 11:11, e0165936. [Crossref]

13. Nataly Woollett, Lucie Cluver, Abigail M. Hatcher, Heena Brahmbhatt. 2016. "To be HIV positive is not the end of the world": Resilience among perinatally infected HIV positive adolescents in Johannesburg. Children and Youth Services Review 70, 269-275. [Crossref]

14. Dorothy E. Dow, Elizabeth L. Turner, Aisa M. Shayo, Blandina Mmbaga, Coleen K. Cunningham, Karen O'Donnell. 2016. Evaluating mental health difficulties and associated outcomes among HIV-positive adolescents in Tanzania. AIDS Care 28:7, 825-833. [Crossref] 